University of Wollongong

Research Online

Faculty of Informatics - Papers (Archive)

Faculty of Engineering and Information

Sciences

2010

\title{
A control approach for voltage and frequency regulation of a wind-diesel- battery based hybrid remote area power supply system
}

\author{
Nishad Mendis \\ University of Wollongong, nnrm786@uowmail.edu.au \\ Kashem Muttaqi \\ University of Wollongong, kashem@uow.edu.au \\ Saad Sayeef \\ University of Wollongong, saad@uow.edu.au \\ Sarath Perera \\ University of Wollongong, sarath@uow.edu.au
}

Follow this and additional works at: https://ro.uow.edu.au/infopapers

Part of the Physical Sciences and Mathematics Commons

\section{Recommended Citation}

Mendis, Nishad; Muttaqi, Kashem; Sayeef, Saad; and Perera, Sarath: A control approach for voltage and frequency regulation of a wind-diesel-battery based hybrid remote area power supply system 2010. https://ro.uow.edu.au/infopapers/3531 


\title{
A control approach for voltage and frequency regulation of a wind-diesel-battery based hybrid remote area power supply system
}

\author{
Abstract \\ A novel Remote Area Power Supply (RAPS) system consisting of a Doubly Fed Induction Generator (DFIG) \\ wind turbine generator, synchronous diesel generator system, battery storage system and a dump load is \\ considered in this paper. A control coordination strategy is formulated with a view to regulate the system \\ voltage and frequency within acceptable limits while extracting the maximum power available from the \\ wind. The battery storage unit is used to provide a smooth state transition from Wind-Only (WO) to Wind- \\ Diesel (WD) mode while enabling the DFIG to operate in its maximum power point tracking mode of \\ operation. The dump load is used to absorb the excess energy which cannot be utilised through the \\ battery storage system. The entire RAPS system has been modelled using SimPowerSystem toolbox in \\ MATLAB.

\section{Disciplines} \\ Physical Sciences and Mathematics

\section{Publication Details} \\ N. Mendis, K. M. Muttaqi, S. Sayeef \& S. Perera, "A control approach for voltage and frequency regulation \\ of a wind-diesel-battery based hybrid remote area power supply system," in Proceedings IECON 2010: \\ 36th Annual Conference of the IEEE Industrial Electronics Society, 2010, pp. 3054-3060.
}




\title{
A Control Approach for Voltage and Frequency Regulation of a Wind-Diesel-Battery based Hybrid Remote Area Power Supply System
}

\author{
Nishad Mendis, Student Member, IEEE, Kashem M. Muttaqi, Senior Member, IEEE, Saad \\ Sayeef, Member, IEEE and Sarath Perera, Member, IEEE
}

\begin{abstract}
A novel Remote Area Power Supply (RAPS) system consisting of a Doubly Fed Induction Generator (DFIG) wind turbine generator, synchronous diesel generator system, battery storage system and a dump load is considered in this paper. A control coordination strategy is formulated with a view to regulate the system voltage and frequency within acceptable limits while extracting the maximum power available from the wind. The battery storage unit is used to provide a smooth state transition from Wind-Only (WO) to Wind-Diesel (WD) mode while enabling the DFIG to operate in its maximum power point tracking mode of operation. The dump load is used to absorb the excess energy which cannot be utilised through the battery storage system. The entire RAPS system has been modelled using SimPowerSystem toolbox in MATLAB.
\end{abstract}

Index Terms-Remote Area Power Systems, Doubly Fed Induction Generator, Diesel Generator, Battery Storage System, Dump load and Maximum Power Extraction

\section{INTRODUCTION}

$\mathbf{R}$ EMOTE Area Power Supply (RAPS) systems are intended to supply power to rural and regional communities including islands which do not benefit from the main grid supply system. Currently, majority of such locations are supplied through diesel power based generator systems due to their lower installation cost, reliability and simple operation. One of the major drawbacks of this type of generation is the high cost associated with the fuel price including inefficient operation at low load factor, transportation cost and environmental concerns [1], [2]. Instead, hybrid remote area power supply systems are now considered as a new emerging technology in supplying electricity to isolated and remote areas [3]. Usually, such systems consist of more than one renewable energy source such as wind, solar, hydro and/or non renewable energy resources such as diesel or gas. Depending on the availability of the resources, a proper generation mix can be utilised to form a hybrid RAPS system. These systems can be designed to operate at improved efficiencies while reducing the environmental impact and generation cost. However, there are various challenges associated with designing such power systems. In this regard, voltage and frequency are the most important aspects to be controlled. In addition, power quality

Mr. Nishad Mendis, A/Prof. Kashem M. Muttaqi, Dr. Saad Sayeef and A/Prof. Sarath perera are with the School of Electrical, Computer and Telecommunications Engineering, University of Wollongong, and are Members of the Integral Energy Power Quality and Reliability Centre, NSW 2522, Australia (email: nnrm786@uow.edu.au). issues, coordination among different components, cost effectiveness and optimum operation are some aspects which are still major subjects of interest [4].

Among the variety of wind turbine generating systems, Doubly Fed Induction Generator (DFIG) has become a popular choice for high power wind applications. It offers many advantages over other types of wind turbines which can be found in [4], [5]. However, due to lack of inertial support and limited reactive power generation capacity, the DFIG based wind turbine RAPS systems require other means of support especially during low wind periods. A diesel generator is one of the best options that can provide both inertial and reactive power support to the system. However, the operation of a diesel generator system needs additional operational measures. In this regard, the minimum load condition and start-stop transients have to be considered as major operational constraints to make the operation of the diesel generator system efficient. Depending on the diesel generator connection technology, an energy storage unit can also be included in a wind/diesel hybrid system to improve the supply reliability of the system [6], [7]. For a standalone wind turbine based power system, a battery storage system is seen to be the best option due to its high energy density. In standalone power systems, it is also a common practice to incorporate a dump load to absorb the additional power associated with over generation which cannot be handled by an energy storage system and [4], [8].

Relevant to the work presented in this paper other research work include the operation of an induction machine as a wind turbine generator, a constant speed diesel generator and an energy storage system [6], [7] and [9]. The operation of a permanent magnet machine as the wind turbine generator together with a variable speed diesel generator and an energy storage system is discussed in [1] and [8]. Based on an extensive literature review, it has been noted that no detailed model exist covering hybrid RAPS systems containing DFIG as the main source of energy together with diesel generator and battery storage.

The novel hybrid RAPS system considered in this paper consists of a DFIG (main generator), diesel generator system, dump load and its controller, battery storage system and main loads as shown in Fig. 1. The power flow control of the system is coordinated employing the various system components, with a view to minimise the active and reactive power imbalance of the system while extracting maximum power from wind. 
In this regard, the DFIG system, diesel generator, battery storage system and dump load with their controls are closely examined. The detailed model consists of high order nonlinear models of the system components which exhibit relatively more accurate system dynamics.

The paper is organised as follows. The control coordination strategies adopted to manage the power flow among the different system components are discussed in Section II. Section III discusses the control methodologies adopted for wind turbine generator, diesel generator system, battery energy storage and dump load and its controller. The simulated results demonstrating the behaviour of the proposed RAPS system for variable load and wind conditions are discussed in Section IV. Conclusions are given in Section V.

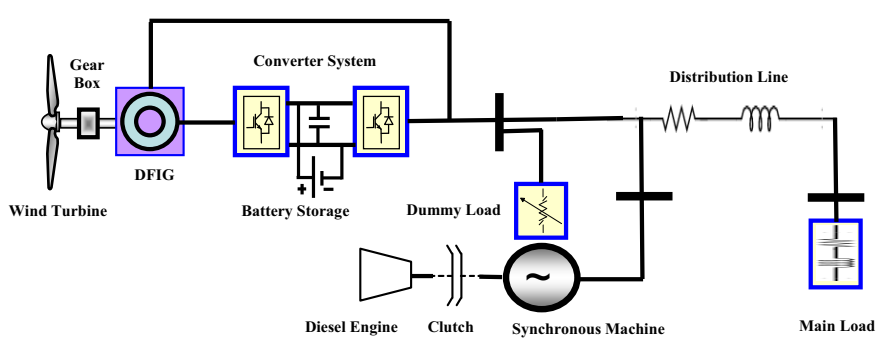

Fig. 1. Proposed RAPS system

\section{Control Coordination of RAPS System FOR Detail Model ANALYSis}

As stated earlier, the system voltage and frequency are the most important quantities to be controlled in a RAPS system. At any given instant, the active power balance of the system should be maintained in order to regulate the system frequency. In general, to achieve an acceptable frequency regulation in a power system, the conditions given by (1) has to be fulfilled. For the proposed RAPS system this can be formally given as (2). Regulation of the system voltage requires maintaining the reactive power balance of the sources and sinks in the system. This can be expressed using (3) [10]. A control coordination method is implemented to maintain the active and reactive power balance of the system. In this paper, the highest emphasis is given to the active power control coordination strategy.

$$
\begin{aligned}
\Sigma P_{\text {sources }}-\Sigma P_{\text {sinks }} & =\frac{d K . E .}{d t}=\frac{d \Sigma J \omega^{2}}{d t}=0 \\
P_{w}+P_{D E} \pm P_{b} & =P_{L}+P_{d}
\end{aligned}
$$

where,

K.E. - kinetic energy of the system, J - moment of inertia of rotating machine and $\omega$ - angular velocity of the rotating machine, $P_{w}$ - wind power, $P_{D E}$ - diesel power, $P_{b}$ - battery power, $P_{d}$ - dummy power and $P_{L}$ - load demand of the system.

$$
\Sigma Q_{\text {sources }}-\Sigma Q_{\text {sinks }}=0
$$

\section{A. Reactive Power Control Coordination}

The DFIG and Synchronous Machine (SM) in Fig. 1 are identified as the main sources of reactive power. The reactive power sharing among these two sources can be accomplished using different methods. However, the reactive power supply to the system through the DFIG is limited as in [11]. Hence, the reactive power sharing can be designed in such that, DFIG only compensates for the no-load reactive power as expressed in [4], while the rest is supplied by the SM. Also, the reactive power sharing between these two sources can be implemented using a pre-determined basis (ie. fraction of the total reactive power is supplied through DFIG and the rest is delivered by the SM). In this regard, the SM is the major contributor of reactive power due to its inherent capability. In this paper, the first method is used to satisfy the reactive power requirement of the system.

\section{B. Active Power Control Coordination}

In this paper, active power sharing among four system components (ie. DFIG, diesel, battery and dump load) is implemented with a view to achieve two objectives. The main objective is to minimise the generation demand mismatch so as to avoid the frequency and voltage excursions in the systems. Second objective is to extract the maximum power from the wind thus enabling the RAPS system to run in its optimum power utilisation mode of operation.

Since the Rotor Side Converter (RSC) control is used to control the voltage and the frequency of the system, Maximum Power Extraction (MPE) cannot be implemented within the inverter controls of the DFIG. Therefore the MPE from wind has to be realised by an alternative method. In this paper, the maximum power extraction from wind has been achieved with the help of the battery storage and dump load. The MPE from wind without associated system losses (ie. ideal condition) can be given as in (4) [12], [13]. With the DFIG frequency control discussed in Section III, $i_{q s}$ represents the active power of the main load and hence, any change in the main load is reflected as a change in $i_{q s}$ which causes a change in $i_{q r}$ and $T_{e}$ as evident from (6) and (7) respectively. By controlling the power flow into the battery storage and dump load using the MPE algorithm, it is possible to impose appropriate torque on the DFIG shaft to extract the maximum power from the wind.

With the control methodology discussed in Section III for DFIG, the frequency of the system is made independent from the loading condition and the rotor speed. Hence, the system frequency cannot be used as an input parameter to implement the control coordination for the system as suggested in [7] and [9]. Therefore, direct active power control has been used to develop the coordination strategy for the system in Fig. 1.

A simplified schematic of the control coordination logic associated with the proposed RAPS system is shown in Fig. 2. It illustrates the decision making process in relation to active power sharing among the different system components employed to minimise the active power imbalance of the system. The details of the proposed control coordination strategy depicted in Fig. 2 is as follows. If the power output of the DFIG, $P_{w}$, is greater than the load power demand, $P_{L}$, 
the battery absorbs the additional power (ie. $P_{w}-P_{L}$ ). If this excess power is greater than the maximum capacity of the battery (ie. $\left(P_{b}\right)_{\max }$ ), the dump load has to absorb the additional power of the system. If the dump load power, $P_{d}$, is higher than its maximum rating (ie. $\left(P_{d}\right)_{\max }$ ), then the wind turbine pitch regulation is activated to control the excess wind power extraction. Furthermore, it is assumed that $P_{w}, P_{D E}$ and $P_{b}$ are sufficient to satisfy the load demand at all times.

If the power output of the DFIG (ie. $P_{w}$ ) is smaller than the load demand (ie. $P_{L}$ ) and the power deficit (ie. $\Delta P_{W L}=$ $\left.P_{w}-P_{L}\right)$ is less than zero, two options have to be considered depending on the magnitude of $\Delta P_{W L}$. If $\Delta P_{W L}$ is less than $30 \%$ of the synchronous generator capacity, the battery storage has to provide the required power deficit together with the DFIG. Otherwise, the synchronous generator should be started to provide the required power. However, in order to maintain a smooth transition from Wind-Only (WO) to Wind-Diesel (WD)/wind-diesel to wind-Only modes of operation and to extract the maximum power from wind, the battery storage of the system should also always be connected to the system with a lower discharge rate.

$$
\begin{aligned}
\left(P_{m}\right)_{\mathrm{opt}} & =k_{o p t}\left[\left(\omega_{r}\right)_{o p t}\right]^{3} \\
k_{o p t} & =\frac{1}{2}\left(C_{p}\right)_{o p t} \rho A\left(\frac{R}{\lambda_{o p t}}\right)^{3}
\end{aligned}
$$

where,

$P_{m}$ - power output from the turbine, $C_{p}$ - power coefficient of turbine, A - area swept by the rotor blades, $\rho$ - air density, $\mathrm{R}$ - radius of blade and $\left(P_{m}\right)_{o p t}$ - maximum power output from the wind

$$
\begin{aligned}
i_{q r} & =-\frac{L_{s}}{L_{m}} i_{q s} \\
T_{e} & =\frac{L_{m}}{L_{s}+L_{m}} \frac{V_{s}}{\omega_{s}} i_{q r}
\end{aligned}
$$

where,

$T_{e}$ - electromagnetic torque of the DFIG, $i_{q r}, i_{q s}$ - rotor and stator q-axis current respectively, $L_{s}, L_{m}$ - stator inductance and magnetising inductance respectively

\section{DFIG AND ITS ASSOCIATED CONTROL}

Since DFIG acts as the major source of energy, the contribution towards the system voltage and frequency regulation should be realised by implementing appropriate control methods within the machine inverter controls. The RSC is used to control the load side voltage and frequency. The Line Side Converter (LSC) is used to control the DC link voltage of the back-to-back converter system while providing the additional reactive power required for the system loads if necessary. The methodologies suggested in [4] are used to model the strategies in managing the RSC and LSC control.

The frequency regulation of the system through the DFIG is achieved by ensuring the indirect stator flux oriented mode of operation of RSC which can be given by condition (6).

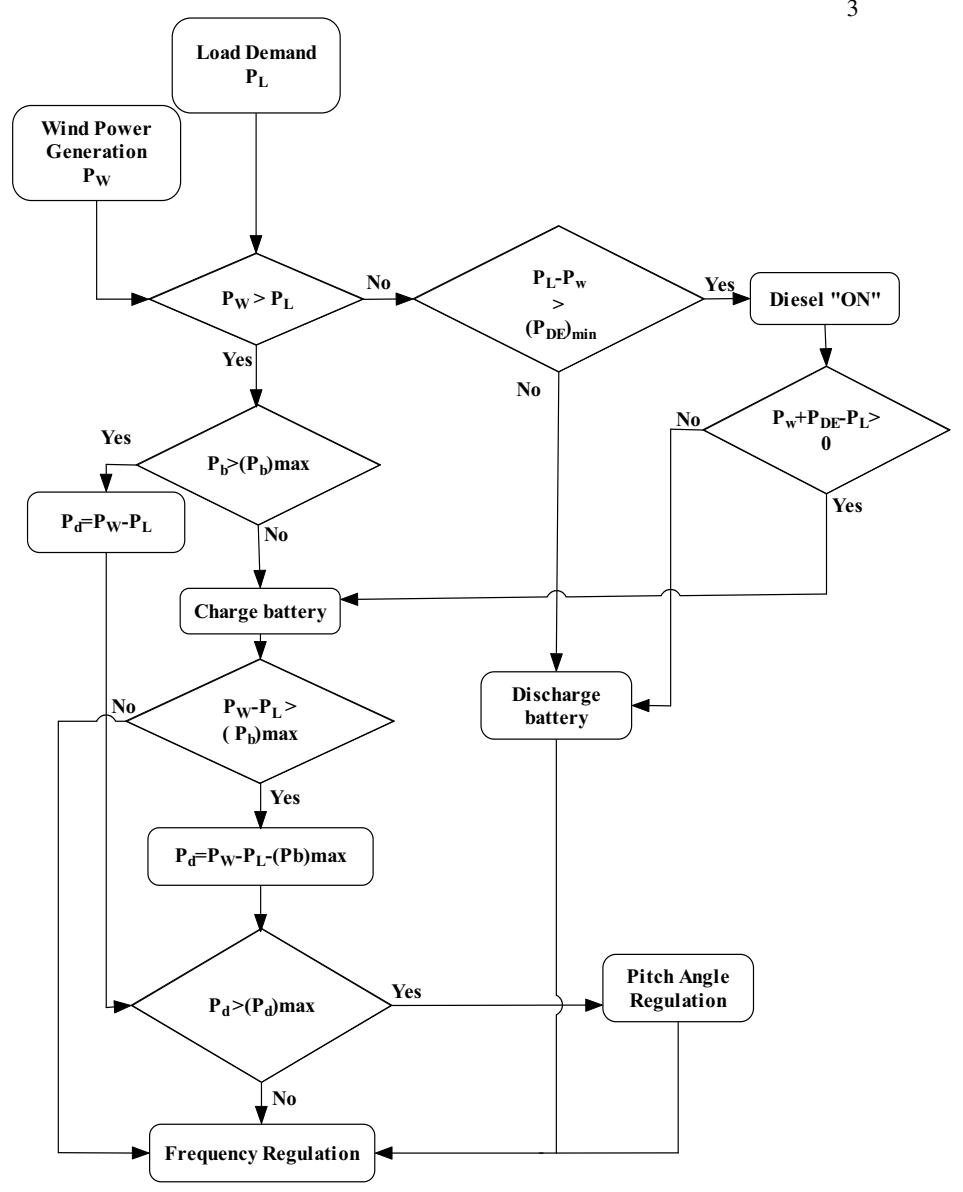

Fig. 2. Instantaneous power flow control of the proposed RAPS system

To provide a better voltage support, the DFIG is modified to compensate its no load reactive power as discussed in [4].

\section{A. Diesel Engine and Synchronous Generator Controls}

The synchronous machine in the RAPS system, shown in Fig. 1, has two modes of operation. It is designed to operate as a Synchronous Condenser (SC) when there is sufficient wind (ie. WO mode) or otherwise as a Synchronous Generator (SG) when there is insufficient wind (ie. WD mode). The two modes of operation of the SM are handled through a friction clutch system as discussed in [9]. When the friction clutch is engaged (ie. clutch signal is "ON"), it allows the transfer of the torque to the SM and if disengaged, the input torque to the SM is set to zero, thus operating it as a SC. The dynamics associated with the friction clutch is shown in Fig. 3. When the clutch is engaged, the shafts of the Diesel Engine (DE) and SM have the same speed and behave as a single shaft. Then the resultant transmitted torque to SM can be derived as in (8) and the diesel engine speed can be expressed using (9).

The generation of the control logic associated with the clutch signal is based on consideration of the following conditions. The block diagram associated with the generation of clutch signal "ON"/“OFF" is shown in Fig. 4.

- The difference between the load power (ie. $P_{L}$ ) and wind power (ie. $P_{w}$ ), should be greater than $30 \%$ of rated capacity of the diesel generator. 
- To couple the generator and engine shafts (ie. clutch engaged state) the speed difference between two shafts should be less than $10^{-3} \mathrm{pu}$.

In this paper, to simplify the simulation of the cranking and firing process of the diesel engine, instead of being stopped or operated at zero speed, the reference speed of the diesel engine is set to $0.3 \mathrm{pu}$ as shown in Fig. 5. When the speed reference is set to $0.3 \mathrm{pu}$, the $\mathrm{SM}$ acts as a $\mathrm{SC}$ as there is no active power transmission to the SM. When the SM acts as a $\mathrm{SG}$, the speed reference is set to $1.0 \mathrm{pu}$. The selection of the two speed references is based on " $D_{\text {on }}$ " and "clutch" signals as shown in Fig. 5. The generation of signal " $D_{\text {on }}$ " is based on the power imbalance associated with load demand and wind power of the system (ie. $P_{L}-P_{w}$ ). A time delay is added to the control signal, " $D_{\text {on }}$ ", to represent the cranking time of the diesel engine.

In addition to the above control, a droop mode control is embedded with the governor system to produce the power deficit of the system which is enabled only when the clutch state is "ON" (ie. SG mode). Otherwise, the power deficit is set to zero. The estimation of the droop setting has been calculated using (10). IEEE type 1 voltage regulator and exciter system is used for the diesel generator. Further details of the exciter modelling can be found in [9].

The estimation of the size of a diesel generator for a renewable energy based power system is still a major subject of interest [14], [15] and is beyond the scope of this paper. In this paper, it is assumed that the synchronous generator is sufficient to provide $30 \%$ of the rated power requirement of the rated load.

$$
\begin{aligned}
T_{c} & =\frac{H_{s} T_{d}+H_{d} T_{s}}{H_{s}+H_{d}} \\
\omega_{d} & =\frac{1}{2 H_{d}} \int\left(T_{d}-T_{c}\right) \\
m & =\frac{\Delta \omega}{P_{\max }}
\end{aligned}
$$

where,

$\Delta \omega$ - maximum acceptable frequency deviation, $P_{\max }$ maximum active power, $T_{c}$ - equivalent torque transmitted to $\mathrm{SM}$ when clutch signal=1, $H_{s}$ and $H_{d}$ - inertia constants of SM and DE, $T_{s}, T_{d}$ - torques of $\mathrm{SM}$ and $\mathrm{DE} \omega_{d}$ - diesel engine speed

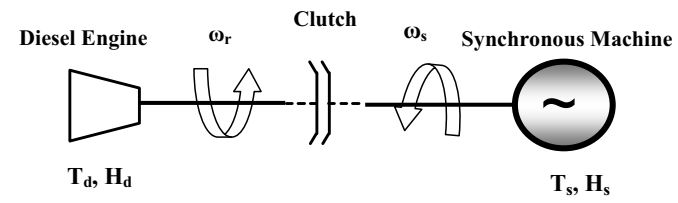

Clutch is "ON" $=1$, "OFF" $=0$

Fig. 3. Dynamics associated with the clutch signal

\section{SUPPLEMENTARY CONTROL}

The supplementary control for the proposed RAPS system in Fig. 1 consists of a Dump Load (DL) and an Energy Storage System (ESS). Supplementary controls are necessary to improve the system operation, reliability and integrity. In this regard, the battery storage unit and dump load are used to maintain the power balance of the system. The following subsections describe the individual controls applied to the energy storage system and dump load.

\section{A. Energy Storage System}

A battery storage system can be identified as a long duration energy storage option as it has a high energy density compared to other available energy storage options [16]. In this paper, the battery storage is connected to the DC link of the DFIG using a two stage bi-directional DC/DC buck-boost converter. The prime objectives of having a battery energy storage system are to minimise the demand generation mismatch when the DG is unable to provide any active power or to ensure a smooth state transition of operation modes (ie. WO $\rightarrow$ WD or WD $\rightarrow \mathrm{WO}$ ). The adopted control strategy of the battery storage system is shown in Fig. 6. The term $\Delta P$ consists of two components which can be described using (11)-(13). The battery storage system controller continuously measures the difference between the actual wind power (ie. $P_{w}$ ) and optimum wind power (ie. $\left(P_{w}\right)_{\text {opt }}$ ) thus enabling the extraction of maximum power from wind. In addition, it also considers the power imbalance of the system which is given by $\Delta P_{w D L}$ in (12). The reference battery current which is derived from 13 , is compared with the actual battery current (ie. $i_{b}$ ) and the error is compensated through a PI controller. The output of the PI controller is compared with a triangular carrier wave to generate the switching signals (ie. $Q_{1}$ and $Q_{2}$ ) for the buckboost converter.

The estimation of the size of energy storage system is extremely site specific. In this paper, the sizing of the battery was estimated based on the condition given in (14). It is assumed that the battery storage system would be able to provide $20 \%$ of the rated system demand(ie. $0.2 \mathrm{pu}$ ).

$$
\begin{aligned}
\Delta P_{w} & =\left(P_{w}\right)_{o p t}-P_{w} \\
\Delta P_{w D L} & =P_{L}-P_{w}-P_{D E} \\
\Delta P & =\Delta P_{w}+\Delta P_{w D L}
\end{aligned}
$$

$0.2 \times I_{\text {rated }} \times\left(\frac{t}{60}\right)=($ Ah rating of the battery $) \times k$

where,

$I_{\text {rated }}$ - rated current of the load demand, $\mathrm{t}$ - time duration that battery provides power into the system and $\mathrm{k}$ - average discharge/charge current of the battery in pu

\section{B. Dump Load and its controller}

The dump load of the system is coordinated with the battery energy storage system to maintain the power balance 


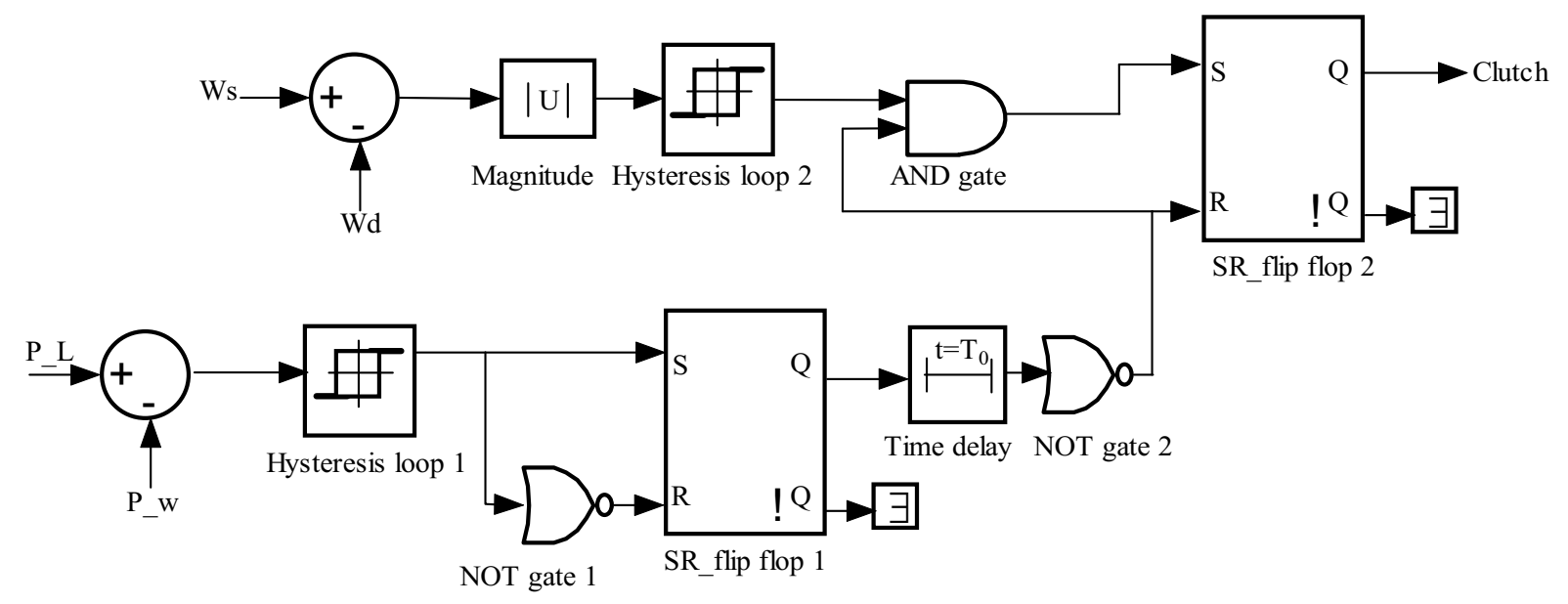

Fig. 4. Generation of clutch signal

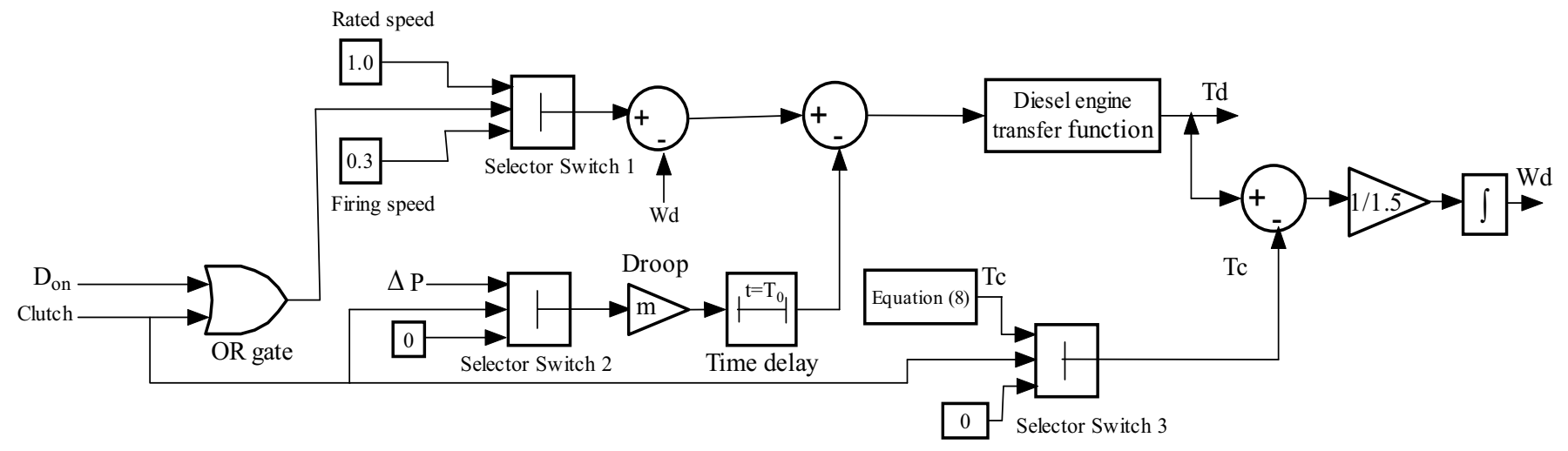

Fig. 5. The model of the diesel engine

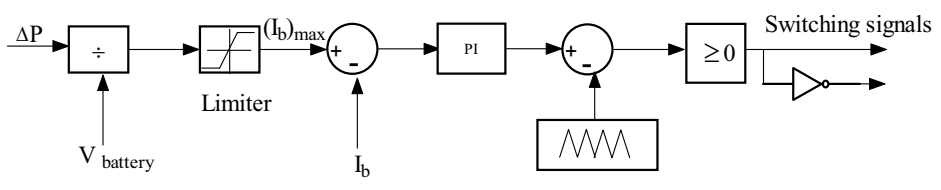

Fig. 6. Battery control strategy

of the system. In practical RAPS systems, a dump load could be a space-heating or water-heating system. This could be represented by a series of resistors which are connected across switches. The resistors operate at zero crossings of the system voltage to ensure minimum impact on the system voltage quality. The necessary and sufficient condition under which it operates is given by (15). The operation of the dump load is limited to when there is additional power available in the system. Also, the dump load will start absorbing the additional power after battery reaches its rated capacity (ie. $\left.\left(P_{b}\right)_{\max }\right)$.

$$
P_{w}+\left(P_{b}\right)_{\max }-P_{L}>0
$$

\section{Simulation Results}

The entire RAPS system was simulated under variable wind and load conditions. In this regard, active power sharing of various components was observed. The coordination of the different system components is the most critical and important aspect to be investigated for stable operation of the entire system. The AC voltage, frequency at Point of Common Coupling (PCC) and DC link stability of the DFIG are also examined.

Fig. 7 shows the system response and Fig. 8 illustrates the power sharing among different system components. The wind condition under which the system has been simulated is shown in Fig. 7-(a). It can be seen that the wind velocity is set initially at $12 \mathrm{~m} / \mathrm{s}$. After $\mathrm{t}=4 \mathrm{~s}$, the wind velocity drops to $9 \mathrm{~m} / \mathrm{s}$, then it is increased to $11 \mathrm{~m} / \mathrm{s}$ at $\mathrm{t}=8 \mathrm{~s}$. The load demand is initially set at $0.6 \mathrm{pu}$. At time $\mathrm{t}=3 \mathrm{~s}$, the load is increased to a value of $0.775 \mathrm{pu}$ and the same load (ie. $0.175 \mathrm{pu}$ ) is disconnected from the system at $\mathrm{t}=9 \mathrm{~s}$ as shown in Fig. 8-(d). The AC voltage at PCC is shown in Fig. 7-(b). It can be seen that the AC load voltage is not affected by the wind speed or resistive load step changes. A sudden voltage excursion can be seen at $t=9.25$ $\mathrm{s}$ which corresponds to the clutch out of the diesel engine (ie. synchronous generator to condenser mode) as evident from Fig. 8-(b). At $t=9.25 \mathrm{~s}$ the $\mathrm{SG}$ goes into the motoring mode before changing to the SC mode of operation thus causing voltage excursions in the system as evident from Fig. 8-(b) and Fig. 7-(b). The load side voltage of the system stays within $\pm 1 \%$ of its rated value during normal operation. Fig. 7-(c) shows the frequency of the system voltage. As expected, it is closely regulated about the rated value of $1.0 \mathrm{pu}$ and is 
not seen to be influenced by the wind speed change, load step change and mode transition of the SM (ie. SC to SG and vice versa). The frequency of the system is maintained within $0.2 \%$ of its rated value during normal operation. The frequency of the system is mainly regulated by the DFIG control applied to its RSC. The proposed frequency control methodology of DFIG is independent from the shaft speed and resistive load condition of the system. Hence, as anticipated, the system frequency is not seen to be affected with the above mentioned transient conditions. The DC link voltage of the DFIG is depicted in Fig. 7-(d). The simulated behaviour of the DC link voltage shows that it is well regulated at its rated value throughout the operation except during load, wind step changes and state transitions of synchronous machine (ie. synchronous condenser to synchronous generator and vice versa). However, the highest DC link voltage variations are seen to occur at $\mathrm{t}=7 \mathrm{~s}$ and $\mathrm{t}=9.25 \mathrm{~s}$ which correspond to the mode transition of the synchronous machine as evident from Fig. 8-(b). Also, during the same time periods the battery storage abruptly changes its direction of power (ie. charging to discharging mode of operation) as evident from Fig. 8-(c). This instantaneous power flow reversal causes the DC link voltage fluctuation which can be described using the capacitor voltage equation (ie. $\left(i_{c}=C \frac{d V}{d t}\right)$ ). Even during the transient conditions, the DC link voltage variation is limited within \pm $5 \%$ of its rated value.

The wind power variation of the system is shown in Fig. 8-(a). For simulation purposes, initially the slip of the wind turbine is set to $\mathrm{s}=-0.1$ which corresponds to super synchronous mode of operation. According to the wind turbine characteristics, the corresponding maximum power output of the wind generator is $0.73 \mathrm{pu}$ at a shaft speed of $1.2 \mathrm{pu}$ for a wind speed of $11 \mathrm{~m} / \mathrm{s}$. From Fig. 8-(a), the power output of the DFIG is seen to rise to a value of $0.73 \mathrm{pu}$ at $\mathrm{t}=4 \mathrm{~s}$. At this time the load demand is set to $0.6 \mathrm{pu}$. The additional power is absorbed by the battery storage unit. At time $t=3 \mathrm{~s}$, the load of the system is increased to $0.775 \mathrm{pu}$ and then the battery storage changes its mode of operation (ie. charging to discharging) and provides the required power deficit demanded by the load. At $\mathrm{t}=4 \mathrm{~s}$, the wind speed is reduced to $9 \mathrm{~m} / \mathrm{s}$ causing reduction in wind power output. When the difference between the load demand and wind power, $P_{L}-P_{w}$, is greater than $0.3 \mathrm{pu}$, the condition under which the diesel generator should operate is fulfilled. However, the synchronous machine still acts as a synchronous condenser and needs extra time to reach its rated speed (ie. $1 \mathrm{pu}$ ) to transfer the required torque to perform as a $\mathrm{SG}$. At $\mathrm{t}=7 \mathrm{~s}$, the $\mathrm{SM}$ changes its mode of operation from SC to $\mathrm{SG}$ as evident from Fig. 8-(b). The diesel generator keeps providing power until the load step down at $t=9 \mathrm{~s}$. During that time period (ie. $\mathrm{t}=7$ to $9 \mathrm{~s}$ ), the battery storage operates as a buffer to ensure maximum power extraction from wind as shown in Fig. 8-(c). After $\mathrm{t}=9 \mathrm{~s}$, the synchronous machine changes its mode of operation from SG to SC and thereby the required power is entirely supplied using the DFIG and battery storage.

The corresponding active power imbalance associated with the entire RAPS system and frequency deviation of the system voltage are shown in Fig. 9-(a) and (b) respectively. It can be seen that the active power imbalance of the system is maintained within 0 to $0.5 \%$ except during the mode transition of the SM (ie. $\mathrm{t}=7.25 \mathrm{~s}$ and $\mathrm{t}=9 \mathrm{~s}$ ). The frequency deviation of the system stays within $\pm 0.5 \%$ of its rated value even during the transient conditions. The maximum power extracted from wind is shown in Fig. 10. It can be seen that the DFIG runs on its maximum power extraction mode of operation except during transient conditions which is unavoidable.
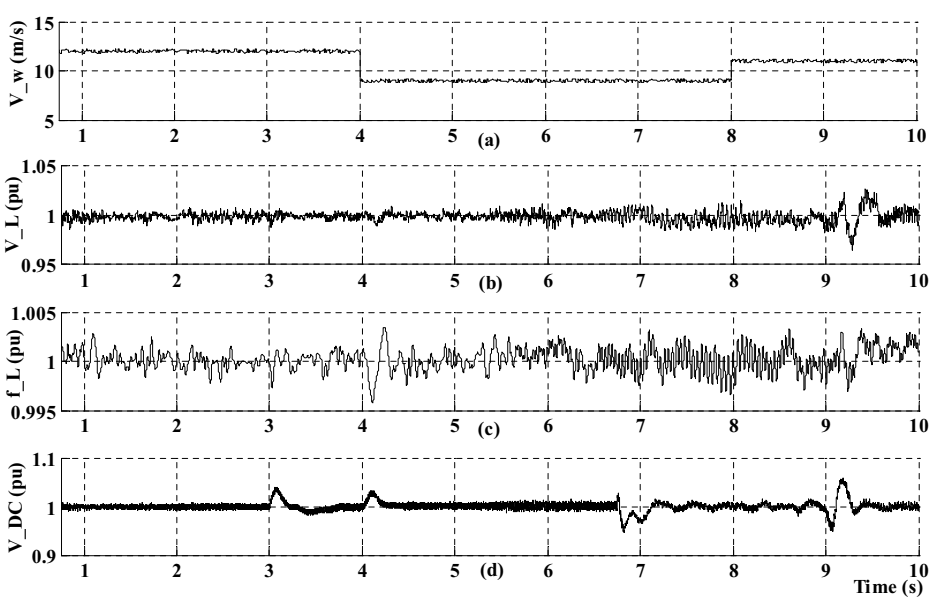

Fig. 7. Response of the RAPS system at variable wind and load conditions. (a) wind speed, (b) voltage at PCC, (c) frequency at PCC, and (d) DC link voltage
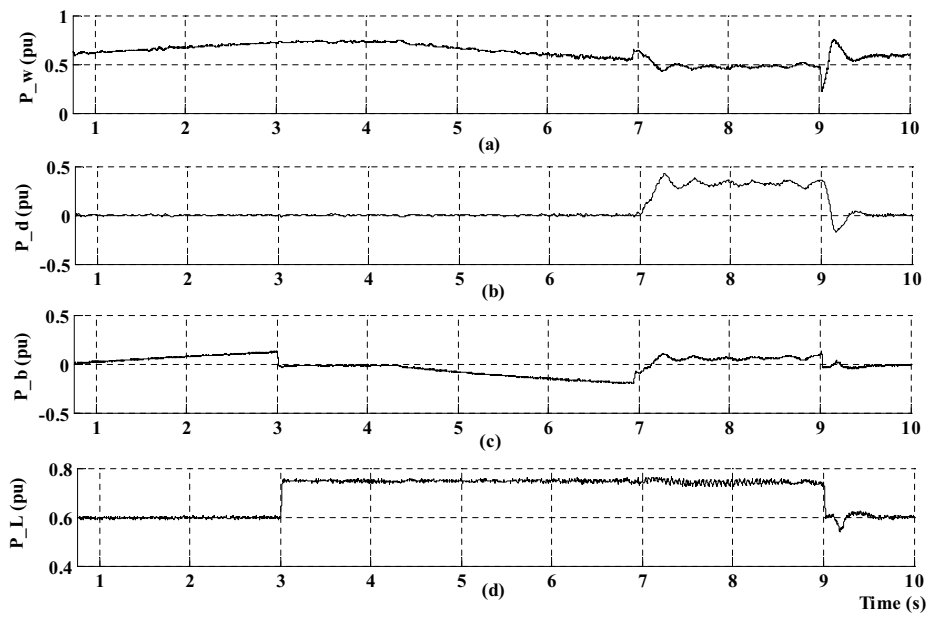

Fig. 8. Power sharing of the RAPS system at variable wind and load conditions. (a) wind power, (b) diesel power, (c) battery power and (d) load demand

\section{CONCLUSIONS}

This paper has investigated the hybrid operation of a novel wind-diesel remote area power system consisting of a battery as a secondary storage of energy. The system performance has been investigated in relation to the bandwidth of the voltage regulation capability under variable load and wind conditions. The system voltage and frequency are regulated within acceptable limits during both steady-state and dynamic conditions including load and wind speed step changes. The mode transition of the synchronous machine which is implemented 

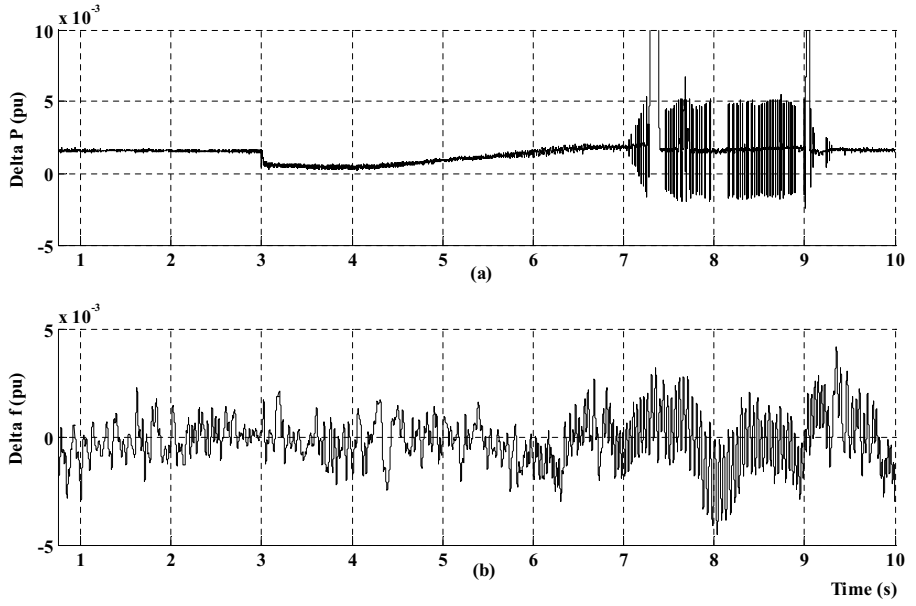

Fig. 9. Frequency and active power deviation of the system (a) active power imbalance and (b) frequency deviation

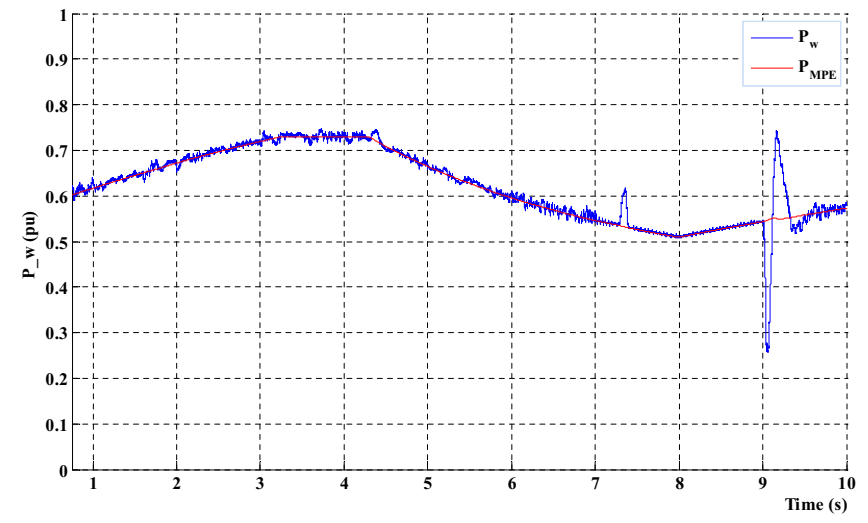

Fig. 10. Maximum power point tracking from wind

using a clutch system provides better active and reactive power support for the system. The control logic associated with the clutch system ensures smooth transition from wind-only to wind-diesel mode of operation and vice versa. The power sharing among the system components has been achieved with minimum power imbalance while extracting the maximum power from the wind.

\section{APPENDIX A}

\section{PARAMETERS OF RAPS SYSTEM- BASE $1000 \mathrm{KW}$}

\begin{tabular}{|c|c|}
\hline \hline Rating of wind turbine generator & $750 \mathrm{~kW}$ \\
\hline Rating of diesel generator & $350 \mathrm{~kW}$ \\
\hline Rating of battery storage system & $150 \mathrm{kWh}$ \\
\hline Allowable SOC of the battery system & $40 \%-80 \%$ \\
\hline DFIG speed range of operation & $0.7 \mathrm{pu}-1.3 \mathrm{pu}$ \\
\hline Rated DC link voltage of back-to-back converter & $750 \mathrm{~V}$ \\
\hline Rated load side voltage & $400 \mathrm{~V}$ \\
\hline Operating frequency & $50 \mathrm{~Hz}$ \\
\hline
\end{tabular}

\section{ACKNOWLEDGEMENTS}

This work is supported by the Australian Research Council (ARC) and Hydro Tasmania Linkage Grant, LP0669245. The authors gratefully acknowledge the support and cooperation of Hydro Tasmania personnel in providing data and advice on the operation of remote area power supply system.

\section{REFERENCES}

[1] Z. Chen and Y. Hu, "A hybrid generation system using variable speed wind turbines and diesel units", IEEE Ind, Electron. Soc. Annual Meeting Conference, Virginia, USA, vol. 3, 2 - 6 Nov. 2003, pp. 2729 - 2734.

[2] W. Koczara, G. Iwanski, B. Kaminski, M. Cirstea and N. Brown, " Power distribution in RES-Diesel autonomous power system with doubly fed induction generator for reduction of fuel consumption", International Conference on Optimization of Electrical and Electronic Equipments, Brasov, Romania, 22 - 24 May 2008, pp. 339 - 344.

[3] T. Senjyu, T. Nakaji, K. Uezato and T. Funabashi, "A Hybrid Power System Using Alternative Energy Facilities in Isolated Island", IEEE Transaction on Energy Conversion, vol. 20, issue 2, Jun. 2005, pp. 406414.

[4] N. Mendis, K. Muttaqi, S. Sayeef and S. Perera, " Power generation in isolated and regional communities: Application of a doubly-fed induction generator based wind turbine", 19th Australasian Universities Power Engineering Conference, Adelaide, Australia, 27 - 30 Sept. 2009, pp. $1-7$.

[5] S. Li and T.A Haskew, "Analysis of Decoupled d-q Vector Control in DFIG Back-to-Back PWM Converter", Power Engineering Society General Meeting, Tampa, Florida, 24 - 28 Jun. 2007, pp. 1 - 7.

[6] E. Muljadi and J.T. Bialasiewicz, "Hybrid power system with a controlled energy storage", IEEE Ind, Electron. Soc. Annual Meeting Conference, Virginia, USA, vol. 2, 2 - 6 Nov. 2003, pp. 1296 - 1301.

[7] R. Takahashi and J. Tamura, "Frequency control of isolated power system with wind farm by using Flywheel Energy Storage System”, 18th International Conference on Electrical Machines, Vilamoura, Portugal, 6 - 9 Sept. 2008.

[8] L.M Grzesiak, W. Koczara and M. da Ponte, "Novel hybrid load-adaptive variable-speed generating system", IEEE International Symposium on Industrial Electronics, vol. 1, 7 - 10 Jul. 1998, pp. 271 - 276.

[9] R. Sebastian, "Smooth transition from wind only to wind diesel mode in an autonomous wind diesel system with a battery-based energy storage system", International Journal of Renewable Energy - Scince Direct, vol. 33, 4 May 2007, pp. 454 - 466.

[10] S. M. Drouilhelt, "Power Flow Management in a High Penetration Wind-Diesel Hybrid Power System with Short-Term Energy Storage", Windpower Conference, Burlington, Vermont, Jun. 20-23.

[11] T. Lund, P. Sorensen, and J. Ek, "Reactive Power Capability of Doubly Fed Induction Genartors", Electric power system research, Science direct, 25 Apr. 2007, pp. 379 - 394.

[12] T. Luu and A. Nasiri, "Output Power Maximizing of a Wind Turbine by Adjusting Rotor Speed" Conference on Electrical and Computer Engineering, Ontario, Canada, 4 - 7 May 2008, pp. 1591 - 1596.

[13] F. Yu, Q. L Liu and J. Zhang, "Flexible Grid-connection Technique and Novel Maximum Wind Power Tracking Algorithm for Doubly-Fed Wind Power Generator", IECON 33rd Annual Conference, Taipei, Taiwan, 5 8 Nov. 2007, pp. 2098 - 2103.

[14] F. Katiraei and C. Abbey, "Diesel Plant Sizing and Performance Analysis of a Remote Wind-Diesel Microgrid", Power Engineering Society General Meeting, Tampa, Florida, USA, 24 - 28 Jun. 2007, pp. 1 - 8.

[15] S. Sayeef, N. Mendis and K. Muttaqi, "Optimisation of Component Sizes for a Hybrid Remote Area Power Supply System", 19th Australian Power Engineering Conference, Adelaide, Australia, 2730 Sept. 2009, pp. $1-6$.

[16] L. Wei and G. Joos, "A Power Electronic Interface for a Battery Supercapacitor Hybrid Energy Storage System for Wind Applications", Power Electronics Specialists Conference, Rhodes, Greece , 15 - 19 Jun. 2009, pp. 1762 - 1768. 